\title{
BMJ Open Predictors of physical activity among older adults in Germany: a nationwide cohort study
}

\author{
Kristin Manz, Gert B M Mensink, Susanne Jordan, Anja Schienkiewitz, \\ Susanne Krug, Jonas D Finger
}

To cite: Manz K, Mensink GBM, Jordan S, et al. Predictors of physical activity among older adults in Germany: a nationwide cohort study. BMJ Open 2018;8:e21940. doi:10.1136/ bmjopen-2018-021940

- Prepublication history and additional material for this paper are available online. To view these files, please visit the journal online (http://dx.doi. org/10.1136/bmjopen-2018021940).

Received 25 January 2018 Revised 22 March 2018 Accepted 6 April 2018
Check for updates

Department of Epidemiology and Health Monitoring, Robert Koch Institute, Berlin, Germany

Correspondence to

Dr Jonas D Finger;

FingerJ@rki.de

\section{ABSTRACT}

Objectives To investigate individual, interpersonal and environmental baseline factors predicting regular aerobic physical activity (PA) participation among older adults in Germany at follow-up 12 years later.

Design Population-based cohort study.

Setting Cluster-randomised general population sample selected based on population registry address information from 130 nationally distributed sample points collected from 1997 to 1999 and re-evaluated 12 years later from 2008 to 2011.

Participants 1184 adults, aged 65 years or older at follow-up with complete data at baseline and follow-up, were included in the final study sample.

Outcome measure Regular 'aerobic PA $\geq 1$ day/week' assessed based on self-reported information.

Results At follow-up, $53.2 \%$ of the participants engaged in aerobic PA $\geq 1$ day/week. Participants aged 50 to 60 years at baseline were more likely to engage in aerobic $\mathrm{PA} \geq 1$ day/week than participants aged 61 to 78 years; OR $1.88,95 \% \mathrm{Cl} 1.46$ to 2.40 . Participants with middle and high socioeconomic status (SES) were more likely to engage in aerobic $P A \geq 1$ day/week than participants with Iow SES; OR middle SES 2.08, 1.33 to 3.25; high SES $3.44,2.11$ to 5.60 . Participants with high social support were more likely to engage in aerobic $\mathrm{PA} \geq 1$ day/week at follow-up than participants with low social support; OR $1.98,1.26$ to 3.12 . Furthermore, participants who engaged in leisure time PA at least once per week at baseline were more likely to engage in aerobic $P A \geq 1$ day/week at followup than those who engaged less than once per week; OR $1.95,1.46$ to 2.60 .

Conclusions Several influencing factors assessed at baseline predicted regular aerobic PA participation 12 years later. These factors should be considered when planning interventions to prevent physical inactivity in older adults. There is great potential to increase aerobic PA participation in older adults in Germany, in particular among those with low SES and low social support.

\section{BACKGROUND}

In Germany, $50 \%$ of adults aged 65 years and older suffer from at least three chronic diseases. ${ }^{1}$ Physical activity (PA) can play a major role in preventing multimorbidity in this age group because of the wide range of health conditions which can be positively

\section{Strengths and limitations of this study}

- This study pairs some of the advantages of a nationwide, population-based survey with a cohort study design.

- Another strength is the long average follow-up period of 12 years.

- A limitation is the assessment of the outcome indicators with self-reports on physical activity level that are prone to recall and social desirability bias.

- The study sample size of 1184 persons is appropriate to conduct analysis based on the whole sample but limited to conduct subgroup analysis.

influenced by PA. ${ }^{2}$ Regular PA in older adults contributes to a variety of health benefits such as lower risks of cardiovascular diseases, ${ }^{3}$ functional limitations, ${ }^{4}$ dementia $^{5}$ and all-cause mortality $^{6}$ as well as better psychological wellbeing. ${ }^{3}$ Furthermore, PA plays an important role in the treatment and management of many chronic diseases and conditions such as hypertension, hyperlipidaemia, type 2 diabetes and obesity. ${ }^{3}$ Low-intensity PA can improve the health status of the sedentary elderly, and moderate-intensity and vigorous-intensity aerobic PAs may be even more beneficial. ${ }^{478}$ WHO recommends that older adults engage in moderate-intensity aerobic PA of at least 150 min per week or vigorous-intensity aerobic PA of at least 75 min per week. ${ }^{9}$ However, in many countries, the majority of the elderly population does not achieve the WHO recommendation. ${ }^{10}$ In Germany, three-quarters of women and three-fifths of men aged 65 years and older engage in less than 150 min of aerobic PA per week, and half of them engage in less than 1 day per week of aerobic PA. ${ }^{11}$ In the context of population ageing, this observation demonstrates the potential of PA promotion to support healthy ageing, which is defined by WHO as 'developing and maintaining the functional ability that enables well-being in older age'. 
Therefore, to effectively promote PA and plan interventions, further knowledge is needed about factors influencing PA in older adults and groups at risk for an inactive lifestyle. Ecological models are commonly used to select and structure determinants of PA behaviour. ${ }^{12}$ These models imply that factors from multiple levels (eg, individual, interpersonal, environment, policy and global) influence PA. PA behaviour of older adults is structured in a similar way, with multiple levels of influencing factors: individual factors, for example, age, sex and physical health ${ }^{13}{ }^{14}$; interpersonal factors, for example, living with a spouse and social support ${ }^{14}$ and environmental factors, for example, the built environment. ${ }^{1315}$ However, the evidence in the literature on determinants of regular PA in older adults based on cohort study data is limited. ${ }^{13}$

This study aimed to investigate predictors of regular aerobic PA among older adults living in Germany using data from a nationwide, population-based cohort study.

\section{METHODS}

\section{Study design and participants}

Data from the German National Health Interview and Examination Survey for adults 1997-1999 (GNHIES98) baseline survey and its first follow-up wave 2008-2011 (DEGS1) were used. GNHIES98 and DEGS1 are components of the national German Federal Health Monitoring programme, operated by the Robert Koch Institute, which monitors the health status and health behaviour of adults 18 years and older in Germany. The survey study design is described in detail elsewhere. ${ }^{16}{ }^{17}$ In summary, GNHIES98 and DEGS1 are both nationwide, population-based health examination surveys. Individuals from the general adult population were randomly selected in 130 nationally distributed sample points using a two-stage clustered sampling procedure: initially communities were sampled (primary sample unit) and within these communities address information was randomly drawn from local population registries. Institutionalised persons were excluded from the study sample. The GNHIES98 sample was comprised of 7124 participants between the ages of 18 and 79 years and the DEGS1 sample of 8152 participants between the ages of 18 and 91 years. ${ }^{18} 19$ Interviews, examinations and tests were carried out in both surveys. GNHIES98 data collection was conducted from October 1997 to March 1999, and DEGS1 data collection was conducted from November 2008 to December 2011. GNHIES98 was approved by the Board of the Federal Commissioner for Data Protection Berlin. DEGS1 was approved by the Federal and State Commissioners for Data Protection and by the ethics committee of the Charité-University Medicine Berlin (no EA2/047/08). All participants provided informed written consent.

The response rates were $61 \%$ for GNHIES98\% and $62 \%$ for DEGS1. ${ }^{18} 19$ All GNHIES98 participants were invited to participate in the DEGS1 follow-up survey. To improve the reparticipation rate, participants who moved away or were not willing or able to visit the examination centre had the opportunity to take part in an interview programme. GNHIES98 participants were enrolled in DEGS1 between 10 and 15 years after GNHIES98 participation; 91\% participated 11 to 13 years after GNHIES98. The age range of the study sample for analysis was defined as participants aged 65 years or older at follow-up (DEGS1). This included persons who were aged 50 years or above at baseline (GNHIES98). A flow chart of participants is shown in figure 1. In total, $50.5 \%(\mathrm{n}=1501)$ of GNHIES98 participants, aged 65 years or older at follow-up, participated in DEGS1. Of the $49.5 \%$ non-participants, $19.3 \%$ $(\mathrm{n}=575)$ had died during the follow-up period. A lower reparticipation rate was observed for men, older participants, participants with lower socioeconomic status (SES), participants with chronic disease as well as those with lower leisure time PA (LTPA) level (online supplementary file 1). The final study sample included 1184 participants after the exclusion of participants who were younger than 65 years at follow-up $(n=220)$ and participants with missing data for the PA outcome variable $(n=97)$. The multivariate analysis was conducted based on a complete-case sample ( $\mathrm{n}=1143)$; thus, an additional 41 participants were excluded due to missing data for at least one of the covariates used.

\section{Patient and public involvement}

Patients or public were not involved.

\section{Definition of variables}

\section{Outcome variable}

The participants were asked at follow-up about the number of days and the duration on an average day they engaged in physical activities which made them sweat or get out of breath in an average week. The reference period was the last 3 months. A dichotomous variable was constructed with the categories: 'aerobic PA $\geq 1$ day per week'; yes/no. This cut-off point was chosen because regular aerobic PA on a weekly basis is associated with substantial health benefits. ${ }^{3}$

\section{Predictor variables}

The information used for constructing the exposure variables was assessed in the baseline survey (GNHIES98) with self-administered questionnaires, physician-administered computer-assisted personal interviews (CAPIs) or physical examinations. The variables were selected based on theories and evidence available in the literature. ${ }^{12} 20$ According to the ecological model, individual (demographic variables, health status), interpersonal (living with a spouse, social support), health behavioural (LTPA, participation in a health behaviour change programme, smoking status) and environmental (size of and satisfaction with the living area) factors were included in the analysis.

\section{Individual factors}

Participant SES was assessed using an index based on the educational level, household income and occupational status of the participants which has been described in 
GNHIES98 participants 50 years and older $\mathrm{n}=2974$

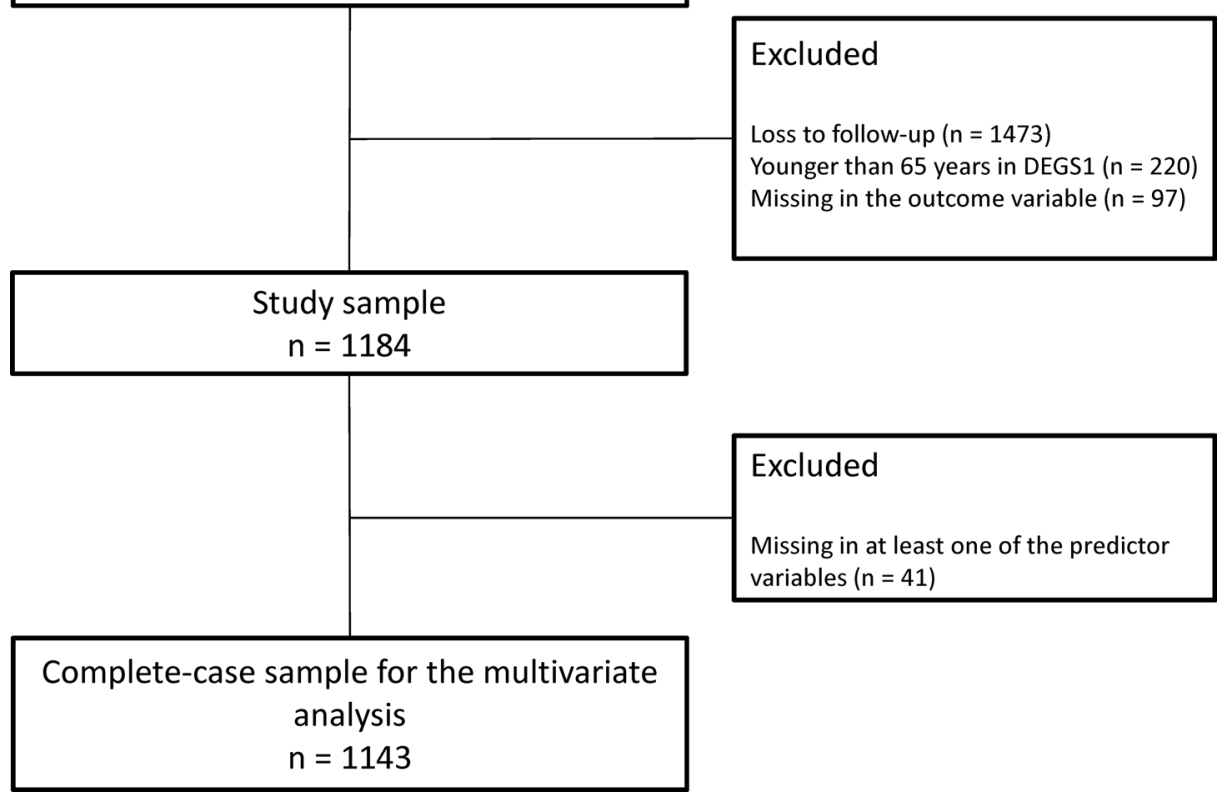

Figure 1 Flow diagram of participants. DEGS1, German National Health Interview and Examination Survey for adults first follow-up wave 2008-2011; GNHIES98, German National Health Interview and Examination Survey for adults $1997-1999$.

detail elsewhere. ${ }^{21}$ The prevalence of chronic diseases was assessed during the CAPI. Participants were defined as 'having a chronic disease' if they indicated diagnosis by a physician of at least one of the following diseases: coronary heart disease, stroke, diabetes, respiratory disease or cancer. Participant body mass index (BMI) was calculated using measured participant weight and height. According to the guidelines of WHO, obesity was defined as BMI $\geq 30 \mathrm{~kg} / \mathrm{m}^{2}{ }^{22}$

\section{Interpersonal factors}

Participants were defined as 'living with a spouse' if they indicated marriage or cohabitation with their spouse. The question 'How many people are so close to you that you can count on them if you have serious personal problems?' derived from the Oslo-3 Social Support Scale ${ }^{23}$ was used as proxy variable for social support. Two categories were constructed: 'low social support' (one person or none) and 'high social support' (at least two persons).

\section{Behavioural factors}

LTPA was assessed with the question, 'On average, how often do you do sports activities or other physical activities in your leisure time, which make you sweat or out of breath?'. The five answer categories were summarised into two categories: 'weekly LTPA' (daily/3 to 6 times a week/1 to 2 times a week) and 'no weekly LTPA' (once a month/never). 'Participation in at least one health behaviour change programme' (abbreviated as 'at least one health programme') was defined if participants reported participation in a programme with the topic 'weight reduction', 'healthy nutrition', 'back training' or 'stress management' during the last 12 months. ${ }^{24}$ The variable should be an indicator for health-oriented behaviour. Participants were defined as 'smoker' if they reported that they currently smoke and were defined as 'non-smoker' if they identified as a former smoker or as having never smoked.

\section{Environmental factors}

A 'residential area size' variable was constructed with four categories: 'rural area' (<5000 inhabitants), 'small-sized city' (5000-<20000 inhabitants), 'medium-sized city' (20 000-<100000 inhabitants) and 'metropolitan city' ( $\geq 100000$ inhabitants). For a subjective estimation of the environment, participants were asked to rate 'satisfaction with their living area' on a seven-point scale (from 1 'very unsatisfied' to 7 'very satisfied'). A dichotomous variable was constructed with the categories 'not satisfied' (points 1-5) and 'satisfied' (points 6 and 7).

\section{Statistical analyses}

All statistical analyses were performed with the survey design procedure of STATA V.14.1 to adjust for cluster design. $\mathrm{P}$ values less than 0.05 were defined as statistically significant. Predictors of aerobic PA $\geq 1$ day/week were investigated in two steps: first, bivariate analyses were performed and second, exposure variables that were significantly associated with the outcome in the bivariate analysis $(\mathrm{p}<0.05)$ were included in a stepwise logistic regression analysis. Bivariate associations between the exposure and outcome variables were analysed with the Pearson's chi-squared test with Rao-Scott correction. In the logistic regression, ORs and $95 \%$ CIs were estimated 
to examine the associations between baseline exposure variables and participation in aerobic PA $\geq 1$ day/week at follow-up. During the stepwise analysis, three models were investigated: Model 1 included individual factors (sex, age, SES, chronic disease and obesity); in Model 2, the interpersonal factors living with a spouse and social support were added and in Model 3, the behavioural variables were added (LTPA, at least one health programme). To detect multicollinearity between the covariates, variance inflation factors (VIFs) were calculated. All VIFs were less than 1.5 and thus clearly lower than the common threshold for multicollinearity of $10 .{ }^{25}$ To investigate whether the predictors of aerobic PA $\geq 1$ day/week differ between men and women and between different age groups, age and sex interaction analyses were performed for all associations presented in Model 3.

\section{RESULTS}

\section{Participants}

In total, $52.5 \% \quad(\mathrm{n}=622)$ of the participants were women. The mean age of the participants at baseline was 60 years (range 50-78 years) and at follow-up 72 years (range $65-91$ years $)$. Overall, $60.2 \%(n=713)$ were in the age group ' $50-60$ years' at baseline and $39.8 \%(n=471)$ in the age group '61-78 years'. The description of the participants according to sociodemographic, health-related, interpersonal, behavioural and environmental variables at baseline is presented in table 1. When comparing participants from the older age group (61-78 years) to participants from the younger age group (50-60 years) at baseline, older participants had high SES less often, had a chronic disease more often, lived with a spouse less often, participated in LTPA less often, participated in a health programme less often and smoked less often than younger participants (each $\mathrm{p}<0.05)$.

\section{Aerobic $\mathrm{PA} \geq 1$ day/week}

In total, $53.2 \%$ of the participants engaged in aerobic PA $\geq 1$ day/week at follow-up. No significant difference was observed between men and women $(55.3 \%$ vs $51.3 \% ; \mathrm{p}=0.158)$. The prevalence of engaging in aerobic $\mathrm{PA} \geq 1$ day/week $(41.2 \%)$ was lower at baseline among the 61-year to 78-year age group than among the 50-year to 60-year age group, where prevalence was $61.2 \%$ $(\mathrm{p}<0.001)$. The prevalence of aerobic PA $\geq 1$ day/week according to baseline sociodemographic, health-related, behavioural, social and environmental variables is shown in table 2.

\section{Predictors of engaging in aerobic $\mathrm{PA} \geq 1$ day/week}

Binary analyses showed (table 2) that age, SES, chronic disease, obesity, living with a spouse, social support, LTPA and participation in at least one health programme at baseline were significantly associated with aerobic $\mathrm{PA} \geq 1$ day/week at follow-up.

Multivariable analyses showed that age, SES, social support and LTPA were predictors for aerobic PA $\geq 1$ day/ week at follow-up (table 3). The results of Model 3 (all binary significant variables included) indicated that participants aged 50 to 60 years were more likely to engage in aerobic $\mathrm{PA} \geq 1$ day/week than participants aged 61 to 78 years, with an OR of 1.88 (95\% CI 1.46 to 2.40). Participants with middle or high SES were more likely to engage in aerobic $\mathrm{PA} \geq 1$ day/week than participants with low SES, with an OR of 2.08 (1.33 to 3.25) for middle SES and 3.44 (2.11 to 5.60) for high SES. Participants with high social support were more likely to engage in aerobic PA $\geq 1$ day/week at follow-up than participants with a low social support, with an OR of 1.98 (1.26 to 3.12). Furthermore, participants who participate in LTPA every week at baseline were more likely to engage in aerobic $\mathrm{PA} \geq 1$ day/ week at follow-up than inactive participants, with an OR of 1.95 (1.46 to 2.60 ).

\section{Subgroup analyses}

The interaction analyses showed that age was an effect modifier for the association between SES and aerobic PA $\geq 1$ day/week and for the association between social support and aerobic PA $\geq 1$ day/week (interaction term age*middle SES: $\mathrm{p}=0.033$; age*high SES: $\mathrm{p}<0.001$; age* so- $^{*}$ cial support: $\mathrm{p}<0.001)$. Subgroup analyses showed that SES was a significant determinant of aerobic PA $\geq 1$ day/ week only in the age group 65 to 72 years but not in the age group 73 to 91 years. Participants in this age group with middle or high SES were more likely to engage in aerobic $\mathrm{PA} \geq 1$ day/week than participants with low SES (middle SES: $3.02,1.70$ to 5.37; high SES: $6.62,3.74$ to 11.72). Furthermore, social support was only a significant determinant of aerobic PA $\geq 1$ day/week among participants 65 to 72 years. Participants in this age group with higher social support were more likely to engage in aerobic $\mathrm{PA} \geq 1$ day/ week, with an OR of 3.31 (1.76 to 6.21). Sex was not an effect modifier for any of the presented associations.

\section{DISCUSSION}

In this nationwide, population-based cohort study, it was observed that half of the older adults $65+$ years in Germany did not engage in aerobic PA at least 1 day per week. The multivariable analyses showed that the groups at high risk for having an inactive lifestyle at age $65+$ years were those who, 12 years earlier, were in the older age groups, those with low socioeconomic position, low social support and low previous levels of PA. Several additional determinants of aerobic PA identified in binary analyses were no longer associated with the outcome after multivariable adjustment.

\section{Individual factors}

Sex was not a predictor for aerobic PA $\geq 1$ day/week in older adults in the present study. Other studies with older adults showed mixed results with a tendency to report a higher PA level for men. ${ }^{10} 1314$ A time trend analysis on the prevalence of physical inactivity among German adults aged 25 to 69 years over an observation period of 
Table 1 Baseline characteristics of the study sample $(n=1184)$

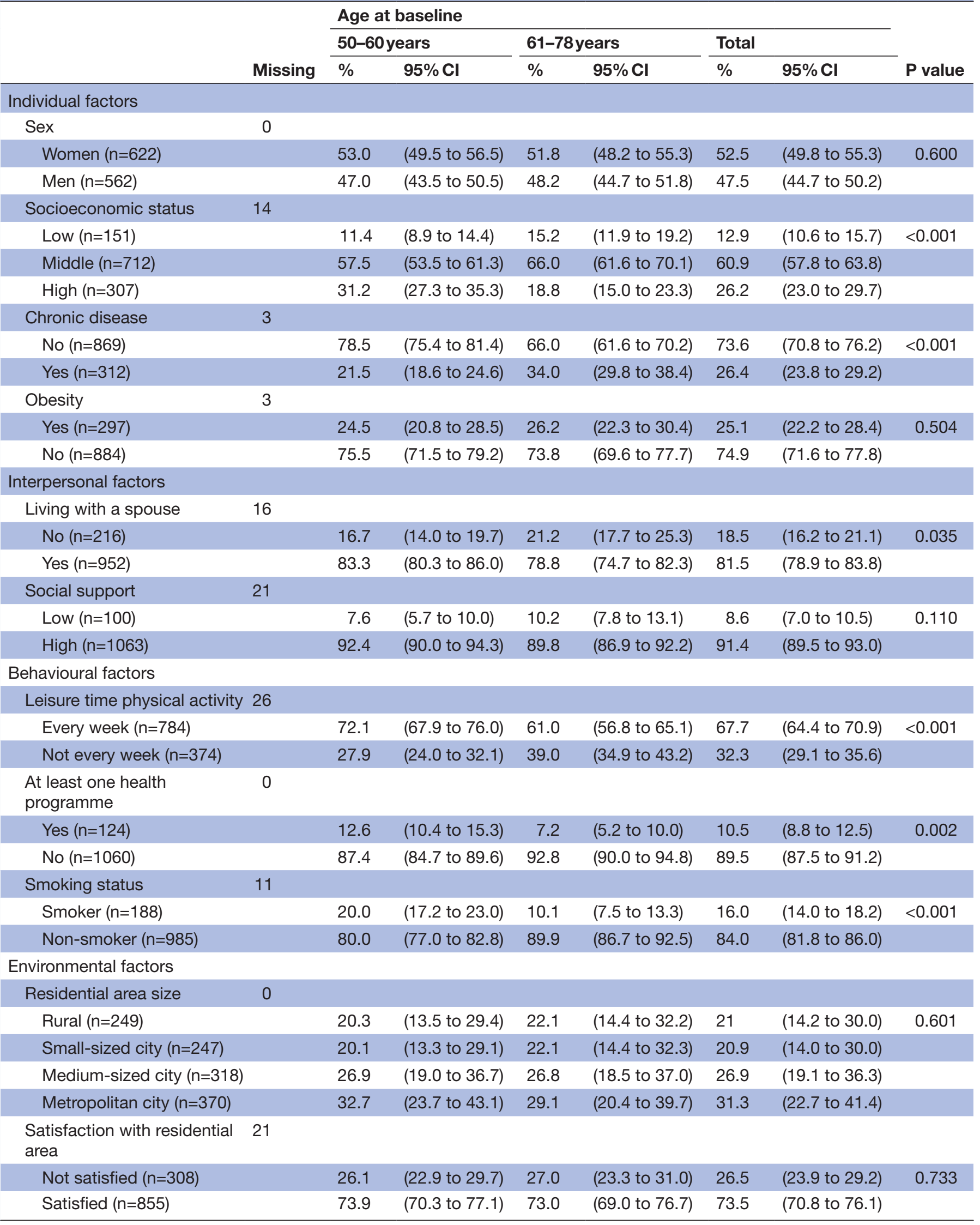


Table 2 Bivariate associations between aerobic PA $\geq 1$ day/week and potential predictor variables

\section{Aerobic $\mathrm{PA} \geq 1$ day/week}

\begin{tabular}{|c|c|c|c|c|c|c|}
\hline & & \multicolumn{2}{|l|}{ Yes } & \multicolumn{2}{|l|}{ No } & \multirow[b]{2}{*}{ P values* } \\
\hline & & $\%$ & $95 \% \mathrm{Cl}$ & $\%$ & $95 \% \mathrm{Cl}$ & \\
\hline \multicolumn{7}{|c|}{ Sex } \\
\hline & Men $(n=562)$ & 44.7 & (40.1 to 49.4 ) & 55.3 & (50.6 to 59.9 ) & \\
\hline & Age group & & & & & $<0.001$ \\
\hline & $61-78$ years $(n=471)$ & 58.8 & (54.1 to 63.4$)$ & 41.2 & (36.6 to 45.9 ) & \\
\hline & \multicolumn{6}{|l|}{ Socioeconomic status } \\
\hline & Low $(n=151)$ & 70.2 & (62.0 to 77.3 ) & 29.8 & (22.7 to 38.0$)$ & $<0.001$ \\
\hline & Middle $(n=712)$ & 47.9 & (43.8 to 52.0 ) & 52.1 & (48.0 to 56.2 ) & \\
\hline & High $(n=307)$ & 31.9 & (27.0 to 37.3 ) & 68.1 & (62.7 to 73.0$)$ & \\
\hline & \multicolumn{6}{|l|}{ Obesity } \\
\hline & Yes $(n=297)$ & 53.5 & (47.4 to 59.5$)$ & 46.5 & (40.5 to 52.6$)$ & 0.005 \\
\hline & No $(n=884)$ & 44.6 & (41.2 to 48.0 ) & 55.4 & (52.0 to 58.8$)$ & \\
\hline \multirow[t]{5}{*}{2} & \multicolumn{6}{|l|}{ Living with a spouse } \\
\hline & No $(n=216)$ & 57.4 & (51.1 to 63.4$)$ & 42.6 & (36.6 to 48.9 ) & $<0.001$ \\
\hline & Yes $(n=952)$ & 44.1 & (40.5 to 47.8 ) & 55.9 & (52.2 to 59.5$)$ & \\
\hline & \multicolumn{6}{|l|}{ Social support } \\
\hline & Low $(n=100)$ & 65.0 & (55.4 to 73.5$)$ & 35.0 & (26.5 to 44.6$)$ & $<0.001$ \\
\hline \multirow{4}{*}{3} & No $(n=1060)$ & 48.2 & (44.8 to 51.7 ) & 51.8 & (48.3 to 55.2 ) & \\
\hline & \multicolumn{6}{|l|}{ Smoking status } \\
\hline & Smoker $(n=188)$ & 49.5 & (41.7 to 57.3$)$ & 50.5 & (42.7 to 58.3 ) & 0.406 \\
\hline & Non-smoker $(n=985)$ & 46.0 & (42.5 to 49.5$)$ & 54.0 & (50.5 to 57.5$)$ & \\
\hline \multirow[t]{8}{*}{4} & Residential area size & & & & & \\
\hline & Rural $(n=249)$ & 48.6 & (42.1 to 55.1$)$ & 51.4 & (44.9 to 57.9 ) & 0.873 \\
\hline & Small-sized city $(n=247)$ & 48.2 & (39.4 to 57.1$)$ & 51.8 & (42.9 to 60.6$)$ & \\
\hline & Medium-sized city $(n=318)$ & 45.9 & (39.6 to 52.4$)$ & 54.1 & (47.6 to 60.4$)$ & \\
\hline & Metropolitan city $(n=370)$ & 45.4 & $(40.5$ to 50.4$)$ & 54.6 & (49.6 to 59.5$)$ & \\
\hline & \multicolumn{4}{|l|}{ Satisfaction with residential area } & & 0.711 \\
\hline & Not satisfied $(n=308)$ & 47.1 & (42.0 to 52.2$)$ & 52.9 & (47.8 to 58.0$)$ & \\
\hline & Satisfied $(n=855)$ & 46.0 & (42.2 to 49.7$)$ & 54.0 & (50.3 to 57.8$)$ & \\
\hline
\end{tabular}

1: individual factors; 2: interpersonal factors; 3: behavioural factors; 4: environmental factors.

*Pearson's chi-squared test with Rao-Scott correction.

PA, physical activity.

20 years demonstrated that gender differences observed in the first 1990-1992 survey diminished over time so that women were no longer more inactive than men in the
2008-2011 survey. ${ }^{26}$ The higher proportion of women than men aged 65 years and older living in Germany participating in PA courses as part of primary prevention 
Table 3 Stepwise-adjusted ORs of aerobic PA at follow-up by baseline predictor variables, adults aged 65 years or older

\begin{tabular}{|c|c|c|c|c|c|c|}
\hline \multirow[b]{3}{*}{ Baseline variables } & \multicolumn{6}{|c|}{ Aerobic PA $\geq 1$ day/week } \\
\hline & \multicolumn{2}{|c|}{ Model 1} & \multicolumn{2}{|c|}{ Model 2} & \multicolumn{2}{|c|}{ Model 3} \\
\hline & OR & $95 \% \mathrm{Cl}$ & OR & $95 \% \mathrm{Cl}$ & OR & $95 \% \mathrm{Cl}$ \\
\hline \multicolumn{7}{|l|}{ Sex } \\
\hline Women & 0.95 & (0.73 to 1.23 ) & 1.01 & (0.78 to 1.32$)$ & 1.05 & (0.80 to 1.38$)$ \\
\hline Men & 1.00 & - & 1.00 & - & 1.00 & - \\
\hline \multicolumn{7}{|l|}{ Age group } \\
\hline $50-60$ years & 2.00 & (1.56 to 2.56$)$ & 1.97 & (1.53 to 2.52$)$ & 1.88 & (1.46 to 2.40$)$ \\
\hline $61-78$ years & 1.00 & - & 1.00 & - & 1.00 & - \\
\hline \multicolumn{7}{|c|}{ Socioeconomic status } \\
\hline Low & 1.00 & - & 1.00 & - & 1.00 & - \\
\hline Middle & 2.48 & (1.61 to 3.84$)$ & 2.39 & (1.54 to 3.70$)$ & 2.08 & (1.33 to 3.25$)$ \\
\hline High & 4.52 & (2.83 to 7.23 ) & 4.29 & (2.67 to 6.90$)$ & 3.44 & (2.11 to 5.60$)$ \\
\hline \multicolumn{7}{|l|}{ Chronic disease } \\
\hline No & 1.25 & (0.92 to 1.69 ) & 1.24 & (0.91 to 1.69 ) & 1.21 & (0.89 to 1.66$)$ \\
\hline Yes & 1.00 & - & 1.00 & - & 1.00 & - \\
\hline \multicolumn{7}{|l|}{ Obesity } \\
\hline No & 1.23 & (0.93 to 1.62$)$ & 1.24 & (0.94 to 1.63 ) & 1.14 & (0.86 to 1.52$)$ \\
\hline Yes & 1.00 & - & 1.00 & - & 1.00 & - \\
\hline \multicolumn{7}{|l|}{ Living with a spouse } \\
\hline Yes & & & 1.36 & (1.00 to 1.84$)$ & 1.31 & (0.96 to 1.79 ) \\
\hline No & & & 1.00 & - & 1.00 & - \\
\hline \multicolumn{7}{|l|}{ Social support } \\
\hline High & & & 2.11 & (1.35 to 3.30$)$ & 1.98 & (1.26 to 3.12$)$ \\
\hline Low & & & 1.00 & - & 1.00 & - \\
\hline \multicolumn{7}{|c|}{ Leisure time physical actvity } \\
\hline Every week & & & & & 1.95 & (1.46 to 2.60$)$ \\
\hline Not every week & & & & & 1.00 & - \\
\hline \multicolumn{7}{|l|}{$\begin{array}{l}\text { At least one health } \\
\text { programme }\end{array}$} \\
\hline Yes & & & & & 1.36 & (0.88 to 2.10$)$ \\
\hline No & & & & & 1.00 & - \\
\hline
\end{tabular}

Bold, $\mathrm{p}<0.05$; Model 1: individual factors; Model 2: +interpersonal factors; Model 3: +behavioural factors.

PA, physical activity.

programmes $^{24}$ might explain the similar PA prevalence in this study.

The observed lower odds for participation in aerobic $\mathrm{PA} \geq 1$ day/week with higher age in the present study are consistent with other studies. ${ }^{10131427}$ The loss of physical function as well as the fear of injuries and falling may play a role in the reduction of the PA level with progression of age.$^{28}$ A qualitative study showed that older adults still believe that PA is inappropriate for older people and might be even harmful. ${ }^{28}{ }^{29}$ Furthermore, a cohort effect might explain, at least partly, the differences between age groups. Beginning in the 1970s, the number of recreational sport offers started to increase in Germany, ${ }^{30}$ thus the younger age group in the previously mentioned study
(22-32 years old in 1970) might have benefited more than the older age group.

Consistent with the findings reported in other studies, older adults with higher SES participated more often in aerobic $\mathrm{PA} \geq 1$ day/week later in life than persons with low SES. ${ }^{142731}$ More social and material resources and more PA friendly neighbourhoods may partly explain the higher activity level of older adults with a higher SES. ${ }^{31}{ }^{32}$ Another important factor might be the difference in PA behaviour earlier in life. Adults with higher levels of education are more physically active in leisure time, perhaps to compensate for work-related inactivity, whereas adults with lower levels of education may have higher PA level during their work time. ${ }^{33}$ With age and retirement, it is likely that 
adults who participate in LTPA continue these activities, whereas adults who had only experienced work-related activity may become inactive.

The results of this study suggest that chronic disease developed earlier in life is not a predictor of aerobic $\mathrm{PA} \geq 1$ day/week in older adults. A cross-sectional study ${ }^{31}$ also observed no relationship between diabetes and hypertension and PA in older adults. However, other prospective studies showed that older adults with poor health status were less likely to be physically active. ${ }^{13} 1435$ Prescribed PA is part of the therapy of several chronic diseases such as heart disease and diabetes. Thus, chronic diseases can act as both barriers to or motivations for PA, which may blur the association over time. It is possible that such a blurring of the association between chronic disease and PA may have occurred in our study. Moreover, participants with chronic diseases had a lower probability of reparticipation (see online supplementary file 1 ), reducing the possibility of rigorously investigating the long-term association between chronic diseases and aerobic $\mathrm{PA} \geq 1$ day/week in our study sample.

Furthermore, obesity was not a predictor of the outcome aerobic PA $\geq 1$ day/week. Results of prospective studies investigating the influence of obesity on PA in the elderly are inconsistent. The authors of a review concluded that the influence of obesity on PA is weak, ${ }^{14}$ whereas the results of the English Longitudinal Study of Ageing observed that obesity is associated with a lower likelihood of being persistently active. ${ }^{27}$ Similar to chronic diseases, obesity may, on the one hand, result in a lower PA level or, on the other hand, as part of a therapy may encourage an increase in activity level. The different directions of this association make it difficult to evaluate the effect of obesity on PA.

\section{Interpersonal factors}

The results of this study suggest that interpersonal factors are important predictors of engaging in aerobic PA $\geq 1$ day/week in older adults. Participants with higher social support were more likely to participate in aerobic PA $\geq 1$ day/week. Social networks could promote PA among older adults by providing information, connecting older adults to resources, such as transport services, and providing encouragement. ${ }^{28} 32$ The results are in line with a cross-sectional study which observed that in elderly people, social isolation is related to negative health behaviour such as physical inactivity. ${ }^{36} 37$ Living with a spouse was not a significant predictor in this analysis but older adults with a partner tended to be more physically active. Further studies observed that older adults who are married are more likely to participate in physical activities later in life. ${ }^{14}$

\section{Behavioural factors}

In the current study, former weekly LTPA was a predictor of aerobic PA $\geq 1$ day/week in older adults. Several studies observed that PA participation earlier in life is an important determinant of physical behaviour among older adults, in line with our observations. ${ }^{298}$ Experiences about physical competence as well as a positive attitude towards PA could explain the tracking of PA behaviour later in life. ${ }^{29}$

Participation inatleastone PA-related health programme was not a significant predictor of aerobic PA $\geq 1$ day/week 12 years later. It could be that programmes, such as back training and stress management, did not prioritise the promotion of aerobic PA, and thus that participation in these programmes had no positive effect on aerobic PA $\geq 1$ day/week. It could also be that the programmes increased PA level in short-term, but there were no longterm effects on aerobic PA level 12 years later.

In this study, smoking was not associated with aerobic PA $\geq 1$ day/week later in life, contrary to studies demonstrating that health risk behaviour such as smoking and physical inactivity often cluster. ${ }^{14} 27$ Due to the high proportion of adults aged 65 years and older living in Germany who quit smoking, ${ }^{39}$ an explanation for the absence of an association between smoking and PA later in life might be that many participants quit smoking during the follow-up period.

\section{Environmental factors}

The environmental factors investigated in the current study did not predict aerobic PA $\geq 1$ day/week in older adults. Environmental characteristics such as urbanisation and satisfaction with the living area are probably long-term characteristics, for which the impact on individual PA behaviour may already have appeared earlier in life. Also, after adjustment for intermediate variables such as PA at baseline, the additional contribution seems small. Furthermore, participants might have moved to another residential area so that the former residential area has minor influence on the activity behaviour 12 years later. Two reviews investigated the relationship between the environmental factors within the neighbourhood and PA in older adults and came up with contradictory findings. The authors of one review ${ }^{40}$ concluded that the majority of studies reviewed observed no relationship between environmental factors (objectively and subjectively measured) and PA behaviour of older adults. The authors of the other review $^{15}$ determined that characteristics of the built environment (objectively measured) are associated with the PA of older adults. Differences in the assessment of environmental characteristics as well as PA could be reasons for the differing results.

\section{Age interactions}

SES and social support were not significant predictors of aerobic PA $\geq 1$ day/week in the older age group but were significant predictors in the younger age group. One explanation for this could be a decline in the prevalence of aerobic PA with increasing age leading to weaker influence of the predictors. A lower PA prevalence also leads to a lower statistical power to determine significant associations. 


\section{Strengths and limitations}

This study pairs some of the advantages of a nationwide, population-based survey with a high degree of representativeness and a cohort study design which provides stronger information on causal inference. Great efforts were made at all stages while conducting GNHIES89 and DEGS1 to reduce potential sources of bias. ${ }^{16} 17$ This comprised measures such as internal and external quality control during field work, anonymous data collection and record keeping, data quality assurance and use of accurate instruments. However, self-reports on PA level are prone to recall and social desirability bias. ${ }^{41}$ Thus, we cannot exclude the possibility that aerobic $\mathrm{PA} \geq 1$ day/ week was over-reported. Also, most of the independent variables were based on self-reports involving the potential of reporting bias. Selection bias could have appeared at different stages (selection of individuals into the study, loss to follow-up, item non-response). This may have influenced the results and may compromise the generalisability of the findings. For instance, we were not able to consider information from participants who had died during the follow-up period. Non-response analysis indicates that the non-responders were older, had a lower level of LTPA and SES on average and more often chronic diseases and obesity compared with the responders. This suggests that the responders are a healthier and fitter group than the non-responders, and that the prevalence of aerobic PA $\geq 1$ day/week at follow-up might be overestimated. In addition, the study results might not apply to elderly individuals living in a nursing home who were not eligible for inclusion into the study sample.

\section{CONCLUSION}

Despite limitations, we conclude that several influencing factors assessed at baseline predicted regular aerobic PA participation 12 years later. These factors should be considered when planning interventions to prevent physical inactivity in older adults. Aerobic PA has many benefits for ageing people and can improve their life in many ways. There is great potential for increasing aerobic PA participation in older adults in Germany. Low PA levels among older adults indicate the need for PA promotion interventions tailored for this age group. Measures promoting a physically active lifestyle during middle age, for example, through workplace interventions, may have positive long-term effects on PA level at older age due to the strong tracking of PA behaviour. Target groups for PA interventions at middle age should be people with low SES and low social support to prevent low PA levels later in life.

\section{Acknowledgements We thank Katherine Ombrellaro for proofreading and language editing.}

Contributors GBMM was involved in the design and conduct of GNHIES98 and DEGS1 in particular for the physical activity questions. SK and KM conceptualised the current study. KM conducted the present analysis and drafted the manuscript. GBMM, SJ, AS and JDF contributed to the analysis plan and interpretation of the results. GBMM, SJ, AS, SK and JDF critically revised it. JDF contributed to the writing of the manuscript. All authors contributed to the interpretation of findings, reviewed, edited and approved the final manuscript.

Funding The Health Surveys GNHIES98 and DEGS1 are funded by the Federal Ministry of Health Germany.

Competing interests None declared.

Patient consent Obtained.

Ethics approval The study GNHIES98 was approved by the Board of the Federal Commissioner Data Protection Berlin. DEGS1 was approved by the Federal and State Commissioners for Data Protection and by the Charité-University Medicine Berlin ethic committee (no EA2/047/08).

Provenance and peer review Not commissioned; externally peer reviewed.

Data sharing statement Datasets of GNHIES98 and DEGS1 are available via Public Use File (http://www.rki.de/DE/Content/Gesundheitsmonitoring/ Forschungsdatenzentrum/informationen_antrag/info_antrag_node.html).

Open Access This is an Open Access article distributed in accordance with the Creative Commons Attribution Non Commercial (CC BY-NC 4.0) license, which permits others to distribute, remix, adapt, build upon this work non-commercially, and license their derivative works on different terms, provided the original work is properly cited and the use is non-commercial. See: http://creativecommons.org/ licenses/by-nc/4.0/

(C) Article author(s) (or their employer(s) unless otherwise stated in the text of the article) 2018. All rights reserved. No commercial use is permitted unless otherwise expressly granted.

\section{REFERENCES}

1. Fuchs J, Busch M, Lange C, et al. Prevalence and patterns of morbidity among adults in Germany. Results of the German telephone health interview survey German Health Update (GEDA) 2009. Bundesgesundheitsblatt Gesundheitsforschung Gesundheitsschutz 2012;55:576-86.

2. World Health Organization. World report on ageing and health. Geneva, Switzerland: World Health Organization, 2015.

3. Chodzko-Zajko WJ, Proctor DN, Fiatarone Singh MA, et al. American College of Sports Medicine position stand. Exercise and physical activity for older adults. Med Sci Sports Exerc 2009;41:1510-30.

4. Paterson DH, Warburton DE. Physical activity and functional limitations in older adults: a systematic review related to Canada's Physical Activity Guidelines. Int J Behav Nutr Phys Act 2010;7:38.

5. Hamer M, Chida Y. Physical activity and risk of neurodegenerative disease: a systematic review of prospective evidence. Psychol Med 2009;39:3-11.

6. Stessman J, Hammerman-Rozenberg R, Cohen A, et al. Physical activity, function, and longevity among the very old. Arch Intern Med 2009;169:1476-83.

7. Mensink GB, Ziese T, Kok FJ. Benefits of leisure-time physical activity on the cardiovascular risk profile at older age. Int $\mathrm{J}$ Epidemiol 1999;28:659-66.

8. Hupin D, Roche F, Gremeaux V, et al. Even a low-dose of moderateto-vigorous physical activity reduces mortality by $22 \%$ in adults aged $\geq 60$ years: a systematic review and meta-analysis. Br J Sports Med 2015;49:1262-7.

9. World Health Organization. Global recommendations on physical activity for health. Geneva, Switzerland: World Health Organization, 2010.

10. Sun F, Norman IJ, While AE. Physical activity in older people: a systematic review. BMC Public Health 2013;13:449.

11. Robert Koch-Institut. Daten und Fakten: Ergebnisse der Studie "Gesundheit in Deutschland aktuell 2012". Berlin: Robert-Koch-Inst, 2014.

12. Bauman $\mathrm{AE}$, Reis RS, Sallis JF, et al. Correlates of physical activity: why are some people physically active and others not? Lancet 2012;380:258-71.

13. Koeneman MA, Verheijden MW, Chinapaw MJ, et al. Determinants of physical activity and exercise in healthy older adults: a systematic review. Int J Behav Nutr Phys Act 2011;8:142.

14. van Stralen MM, De Vries $\mathrm{H}$, Mudde AN, et al. Determinants of initiation and maintenance of physical activity among older adults: a literature review. Health Psychol Rev 2009;3:147-207.

15. Rosso AL, Auchincloss AH, Michael YL. The urban built environment and mobility in older adults: a comprehensive review. J Aging Res $2011 ; 2011: 1-10$. 
16. Bellach BM, Knopf H, Thefeld W. [The German Health Survey. 1997/98]. Gesundheitswesen 1998;60(Suppl 2):S59-68.

17. Scheidt-Nave $C$, Kamtsiuris $P$, Gößwald A, et al. German health interview and examination survey for adults (DEGS) - design, objectives and implementation of the first data collection wave. BMC Public Health 2012;12:730.

18. Kamtsiuris $P$, Lange $M$, Hoffmann R, et al. The first wave of the German Health Interview and Examination Survey for Adults (DEGS1): sample design, response, weighting and representativeness]. Bundesgesundheitsblatt Gesundheitsforschung Gesundheitsschutz 2013;56:620-30.

19. Thefeld W, Stolzenberg H, Bellach BM. [The Federal Health Survey: response, composition of participants and non-responder analysis]. Gesundheitswesen 1999;61(Spec No):S57-61.

20. Koeneman MA, Chinapaw MJ, Verheijden MW, et al. Do major life events influence physical activity among older adults: the Longitudinal Aging Study Amsterdam. Int J Behav Nutr Phys Act 2012;9:147.

21. Lampert T, Kroll L, Müters S, et al. [Measurement of socioeconomic status in the German Health Interview and Examination Survey for Adults (DEGS1)]. Bundesgesundheitsblatt Gesundheitsforschung Gesundheitsschutz 2013;56:631-6.

22. World Health Organization. BMI classification. http://apps.who.int/ bmi/index.jsp? introPage=intro_3.html

23. Dalgard OS, Dowrick C, Lehtinen $\mathrm{V}$, et al. Negative life events, social support and gender difference in depression: a multinational community survey with data from the ODIN study. Soc Psychiatry Psychiatr Epidemiol 2006;41:444-51.

24. Jordan S, von der Lippe E. [Participation in health behaviour change programmes: results of the German Health Interview and Examination Survey for Adults (DEGS1)]. Bundesgesundheitsblatt Gesundheitsforschung Gesundheitsschutz 2013;56:878-84.

25. Hair JF. Multivariate data analysis with readings. Englewood Cliffs, N.J: Prentice Hall, 1995.

26. Finger JD, Busch MA, Du Y, et al. Time trends in cardiometabolic risk factors in adults - Results from three nationwide German examination surveys from 1990-2011. Deutsches Arzteblatt International 2016;113:712-9.

27. Smith L, Gardner B, Fisher A, et al. Patterns and correlates of physical activity behaviour over 10 years in older adults: prospective analyses from the English Longitudinal Study of Ageing. BMJ Open 2015;5:e007423.

28. Franco MR, Tong A, Howard K, et al. Older people's perspectives on participation in physical activity: a systematic review and thematic synthesis of qualitative literature. Br J Sports Med 2015;49:1268-76.
29. Hirvensalo M, Lintunen T. Life-course perspective for physical activity and sports participation. European Review of Aging and Physical Activity 2011;8:13-22.

30. DaCosta L, Maragaya A. Worldwide experiences and trends in sport for all. Meyer \& Meyer: Oxford, 2002.

31. Mesters I, Wahl S, Van Keulen HM. Socio-demographic, medical and social-cognitive correlates of physical activity behavior among older adults (45-70 years): a cross-sectional study. BMC Public Health 2014;14:647.

32. McNeill LH, Kreuter MW, Subramanian SV. Social environment and physical activity: a review of concepts and evidence. Soc Sci Med 2006;63:1011-22.

33. Finger JD, Tylleskär T, Lampert T, et al. Physical activity patterns and socioeconomic position: the German National Health Interview and Examination Survey 1998 (GNHIES98). BMC Public Health 2012;12:1079.

34. Hoebel J, Finger JD, Kuntz B, et al. Changing educational inequalities in sporting inactivity among adults in Germany: a trend study from 2003 to 2012. BMC Public Health 2017;17:547.

35. Hakola L, Hassinen M, Komulainen P, et al. Correlates of low physical activity levels in aging men and women: the DR's EXTRA Study (ISRCTN45977199). J Aging Phys Act 2015;23:247-55.

36. Nicholson NR. A review of social isolation: an important but underassessed condition in older adults. J Prim Prev 2012;33:137-52.

37. Christiansen J, Larsen FB, Lasgaard M. Do stress, health behavior, and sleep mediate the association between loneliness and adverse health conditions among older people? Soc Sci Med 2016;152:80-6.

38. Hamer M, Kivimaki M, Steptoe A. Longitudinal patterns in physical activity and sedentary behaviour from mid-life to early old age: a substudy of the Whitehall II cohort. J Epidemiol Community Health 2012;66:1110-5.

39. Lampert T, von der Lippe E, Müters S. [Prevalence of smoking in the adult population of Germany: results of the German Health Interview and Examination Survey for Adults (DEGS1)]. Bundesgesundheitsblatt Gesundheitsforschung Gesundheitsschutz 2013;56:802-8

40. Van Cauwenberg J, De Bourdeaudhuij I, De Meester F, et al. Relationship between the physical environment and physical activity in older adults: a systematic review. Health Place 2011;17:458-69.

41. Ekelund U, Tomkinson G, Armstrong N. What proportion of youth are physically active? Measurement issues, levels and recent time trends. Br J Sports Med 2011;45:859-65. 


\section{Correction: Predictors of physical activity among older adults in Germany: a nationwide cohort study}

Manz K, Mensink GBM, Jordan S, et al. Predictors of physical activity among older adults in Germany: a nationwide cohort study BMJ Open 2018;8:e021940. doi: 10.1136/ bmjopen-2018-021940

This article was previously published with an error in table 2.

The columns with variable categories 'yes' /'no' were swapped. Below is the updated table 2 .

Bivariate associations between aerobic $\mathrm{PA} \geq 1$ day/week and potential predictor variables

\begin{tabular}{|c|c|c|c|c|c|c|}
\hline & & \multicolumn{4}{|c|}{ Aerobic PA $\geq 1$ day/week } & \multirow[b]{3}{*}{ P value* } \\
\hline & & \multicolumn{2}{|l|}{ No } & \multicolumn{2}{|l|}{ Yes } & \\
\hline & & $\%$ & $95 \% \mathrm{Cl}$ & $\%$ & $95 \% \mathrm{Cl}$ & \\
\hline \multirow[t]{16}{*}{1} & Sex & & & & & \\
\hline & Women $(n=622)$ & 48.7 & $(44.7$ to 52.7$)$ & 51.3 & (47.3 to 55.3$)$ & 0.158 \\
\hline & Men $(n=562)$ & 44.7 & (40.1 to 49.4 ) & 55.3 & (50.6 to 59.9 ) & \\
\hline & Age group & & & & & \\
\hline & $\begin{array}{l}50-60 \text { years } \\
(n=713)\end{array}$ & 38.8 & (35.1 to 42.8 ) & 61.2 & (57.2 to 64.9 ) & $<0.001$ \\
\hline & $\begin{array}{l}\text { 61-78years } \\
(n=471)\end{array}$ & 58.8 & (54.1 to 63.4 ) & 41.2 & (36.6 to 45.9 ) & \\
\hline & $\begin{array}{l}\text { Socioeconomic } \\
\text { status }\end{array}$ & & & & & \\
\hline & Low $(n=151)$ & 70.2 & (62.0 to 77.3 ) & 29.8 & (22.7 to 38.0 ) & $<0.001$ \\
\hline & Middle $(n=712)$ & 47.9 & (43.8 to 52.0 ) & 52.1 & (48.0 to 56.2 ) & \\
\hline & High $(n=307)$ & 31.9 & (27.0 to 37.3 ) & 68.1 & (62.7 to 73.0$)$ & \\
\hline & Chronic disease & & & & & \\
\hline & No $(n=869)$ & 44.1 & (40.5 to 47.7 ) & 55.9 & (52.3 to 59.5 ) & 0.006 \\
\hline & Yes $(n=312)$ & 53.8 & (47.6 to 60.0 ) & 46.2 & (40.0 to 52.4 ) & \\
\hline & Obesity & & & & & \\
\hline & Yes $(n=297)$ & 53.5 & (47.4 to 59.5 ) & 46.5 & (40.5 to 52.6 ) & 0.005 \\
\hline & No $(n=884)$ & 44.6 & (41.2 to 48.0$)$ & 55.4 & (52.0 to 58.8 ) & \\
\hline \multirow[t]{9}{*}{2} & $\begin{array}{l}\text { Living with a } \\
\text { spouse }\end{array}$ & & & & & \\
\hline & No $(n=216)$ & 57.4 & (51.1 to 63.4$)$ & 42.6 & (36.6 to 48.9 ) & $<0.001$ \\
\hline & Yes $(n=952)$ & 44.1 & (40.5 to 47.8 ) & 55.9 & (52.2 to 59.5 ) & \\
\hline & Social support & & & & & \\
\hline & Low $(n=100)$ & 65.0 & (55.4 to 73.5 ) & 35.0 & (26.5 to 44.6 ) & $<0.001$ \\
\hline & High $(n=1063)$ & 44.9 & (41.6 to 48.2$)$ & 55.1 & (51.8 to 58.4$)$ & \\
\hline & $\begin{array}{l}\text { Leisure time } \\
\text { physical activity }\end{array}$ & & & & & \\
\hline & $\begin{array}{l}\text { Every week } \\
(\mathrm{n}=784)\end{array}$ & 38.6 & (34.8 to 42.6$)$ & 61.4 & (57.4 to 65.2 ) & $<0.001$ \\
\hline & $\begin{array}{l}\text { Not every week } \\
(n=374)\end{array}$ & 62.8 & (57.6 to 67.8 ) & 37.2 & (32.2 to 42.4 ) & \\
\hline \multirow[t]{5}{*}{3} & $\begin{array}{l}\text { At least one } \\
\text { health programme }\end{array}$ & & & & & \\
\hline & Yes $(n=124)$ & 34.7 & (26.7 to 43.6$)$ & 65.3 & (56.4 to 73.3$)$ & 0.005 \\
\hline & No $(n=1060)$ & 48.2 & (44.8 to 51.7$)$ & 51.8 & (48.3 to 55.2$)$ & \\
\hline & Smoking status & & & & & \\
\hline & Smoker $(n=188)$ & 49.5 & (41.7 to 57.3 ) & 50.5 & (42.7 to 58.3 ) & 0.406 \\
\hline
\end{tabular}




\begin{tabular}{|c|c|c|c|c|c|c|}
\hline & & \multicolumn{4}{|c|}{ Aerobic PA $\geq 1$ day/week } & \multirow[b]{3}{*}{ P value* } \\
\hline & & \multicolumn{2}{|l|}{ No } & \multicolumn{2}{|l|}{ Yes } & \\
\hline & & $\%$ & $95 \% \mathrm{Cl}$ & $\%$ & $95 \% \mathrm{Cl}$ & \\
\hline & $\begin{array}{l}\text { Non-smoker } \\
(n=985)\end{array}$ & 46.0 & (42.5 to 49.5 ) & 54.0 & (50.5 to 57.5$)$ & \\
\hline \multirow[t]{8}{*}{4} & $\begin{array}{l}\text { Residential area } \\
\text { size }\end{array}$ & & & & & \\
\hline & Rural $(n=249)$ & 48.6 & (42.1 to 55.1 ) & 51.4 & (44.9 to 57.9 ) & 0.873 \\
\hline & $\begin{array}{l}\text { Small-sized city } \\
(n=247)\end{array}$ & 48.2 & (39.4 to 57.1 ) & 51.8 & (42.9 to 60.6 ) & \\
\hline & $\begin{array}{l}\text { Medium-sized } \\
\text { city }(n=318)\end{array}$ & 45.9 & (39.6 to 52.4 ) & 54.1 & (47.6 to 60.4 ) & \\
\hline & $\begin{array}{l}\text { Metropolitan } \\
\text { city }(n=370)\end{array}$ & 45.4 & (40.5 to 50.4 ) & 54.6 & (49.6 to 59.5 ) & \\
\hline & $\begin{array}{l}\text { Satisfaction with } \\
\text { residential area }\end{array}$ & & & & 0.711 & \\
\hline & $\begin{array}{l}\text { Not satisfied } \\
(n=308)\end{array}$ & 47.1 & (42.0 to 52.2 ) & 52.9 & (47.8 to 58.0 ) & \\
\hline & $\begin{array}{c}\text { Satisfied } \\
(n=855)\end{array}$ & 46.0 & (42.2 to 49.7 ) & 54.0 & (50.3 to 57.8 ) & \\
\hline
\end{tabular}

1: Individual factors; 2: Interpersonal factors; 3: Behavioural factors; 4: Environmental factors.

*Pearson's chi-squared test with Rao-Scott correction.

PA, physical activity.

Open access This is an open access article distributed in accordance with the Creative Commons Attribution Non Commercial (CC BY-NC 4.0) license, which permits others to distribute, remix, adapt, build upon this work non-commercially, and license their derivative works on different terms, provided the original work is properly cited, appropriate credit is given, any changes made indicated, and the use is non-commercial. See: http://creativecommons.org/licenses/by-nc/4.0/.

C Author(s) (or their employer(s)) 2019. Re-use permitted under CC BY-NC. No commercial re-use. See rights and permissions. Published by BMJ.

BMJ Open 2019;9:e021940corr1. doi:10.1136/bmjopen-2018-021940corr1

Check for updates 